\title{
Knowledge and perception about climate change and human health: findings from a baseline survey among vulnerable communities in Bangladesh
}

Md lqbal Kabir ${ }^{1,2,4^{*}}$, Md Bayzidur Rahman ${ }^{3}$, Wayne Smith ${ }^{1}$, Mirza Afreen Fatima Lusha ${ }^{4}$, Syed Azim³ and Abul Hasnat Milton ${ }^{1}$

\begin{abstract}
Background: Bangladesh is one of the countries most vulnerable to climate change (CC). A basic understanding of public perception on vulnerability, attitude and the risk in relation to $C C$ and health will provide strategic directions for government policy, adaptation strategies and development of community-based guidelines. The objective of this study was to collect community-based data on peoples' knowledge and perception about CC and its impact on health.

Methods: In 2012, a cross-sectional survey was undertaken among 6720 households of 224 enumeration areas of rural villages geographically distributed in seven vulnerable districts of Bangladesh, with total population of 19,228,598. Thirty households were selected randomly from each enumeration area using the household listing provided by the Bangladesh Bureau of Statistics (BBS). Information was collected from all the 6720 research participants using a structured questionnaire. An observation checklist was used by the interviewers to collect household- and community-related information. In addition, we selected the head of each household as the eligible participant for an interview. Evidence of association between sociodemographic variables and knowledge of CC was explored by cross-tabulation and measured using chi-square tests. Logistic regression models were used to further explore the predictors of knowledge.
\end{abstract}

Results: The study revealed that the residents of the rural communities selected for this study largely come from a low socioeconomic background: only $9.6 \%$ had postsecondary education or higher, the majority worked as day labourer or farmer (60\%), and only $10 \%$ earned a monthly income above BDT 12000 (equivalent to US $\$ 150$ approx.). The majority of the participants (54.2\%) had some knowledge about CC but $45.8 \%$ did not $(p<0.001)$. The majority of knowledgeable participants $(n=3645)$ felt excessive temperature as the change of climate $(83.2 \%)$. Among all the respondents $(n=6720), 94.5 \%$ perceived change in climate and extreme weather events. Most of them (91.9\%) observed change in rainfall patterns in the last 10 years, and $97.8 \%$ people think their health care expenditure increased after the extreme weather events. Age, educational qualification, monthly income, and occupation were significantly associated with the knowledge about climate change $(p<0.001)$. People with higher educational level or who live near a school were more knowledgeable about CC and its impact on health.

\footnotetext{
* Correspondence: mdiqbal.kabir@uon.edu.au

${ }^{1}$ Centre for Clinical Epidemiology and Biostatistics, School of Medicine and

Public Health, Faculty of Health and Medicine, The University of Newcastle, Newcastle, NSW 2308, Australia

${ }^{2}$ National Institute of Preventive and Social Medicine, NIPSOM, Mohakhali,

Dhaka, Bangladesh

Full list of author information is available at the end of the article
}

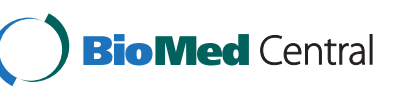

(c) 2016 Kabir et al. Open Access This article is distributed under the terms of the Creative Commons Attribution 4.0 International License (http://creativecommons.org/licenses/by/4.0/), which permits unrestricted use, distribution, and reproduction in any medium, provided you give appropriate credit to the original author(s) and the source, provide a link to the Creative Commons license, and indicate if changes were made. The Creative Commons Public Domain Dedication waiver (http://creativecommons.org/publicdomain/zero/1.0/) applies to the data made available in this article, unless otherwise stated. 
(Continued from previous page)

Conclusions: The knowledge level about CC in our study group was average but the perception and awareness of CC related events and its impact on health was high. The most influential factor leading to understanding of CC and its impact on health was education. School-based intervention could be explored to increase peoples' knowledge about CC and necessary health adaptation at community level.

Keywords: Climate change, Health, Knowledge, Perception, Adaptation, Bangladesh

\section{Background}

The adverse effect of climate change on human health has been recognized relatively late in the development of climate science and policy making $[1,2]$. The recent Fifth Assessment Report (AR5) of the Intergovernmental Panel on Climate Change (IPCC) reinforces the need for societies to take adaptive actions to protect human health from the adverse consequences of climate change [3]. Climate sensitive health determinants and outcomes pose a threat to public health in Least Developed Countries (LDC) [4-6]. To protect health, highly strategic interventions for adaptation will be needed over the next 20-30 years in LDCs such as Bangladesh [7-9].

Climate change $(\mathrm{CC})$ related health risk is a multidimensional and cross cutting issue. To date, a number of studies have suggested that peoples' perception of and attitude towards $\mathrm{CC}$ risk is closely related to adaptative behaviour and mitigation action [10-12]. However, few such studies have been carried out in developing countries [13-16]. Bangladesh is on top of the IPCC risk index of climate victims since 2007 [17].

In this context, epidemiological research has a major role to play in combating CC-related adverse health effects. In a recent cross-sectional study from two villages, one from the northern and another from the southern part of Bangladesh, households' $(n=450)$ perception of human health risks were explored, which suggested the need for further research with a larger sample size to allow generalization [18]. Another study revealed that the public perceptions towards $\mathrm{CC}$, and its impact on health, may inform policies to cope with associated health challenges of CC [19]. In some studies, lay people perceived CC with misconceptions and misunderstandings about its cause and effects [20-22]. These misunderstandings have the propensity to cause fear about the consequences of CC [23]. However, environmental change management and associated education from the government are important to build resilience among the vulnerable communities [24].

Knowledge of CC is a necessary precursor for people to adapt appropriately. The health sector of Bangladesh does not have evidence-based strategies for health adaptation to CC. A survey undertaken by the Ministry of Health and Family Welfare of Bangladesh forms the basis of a future cohort study. Such a study is needed to expand our knowledge of evidence-based translational research, particularly in the context of being one of the most vulnerable LDCs. The objective of this study was to collect baseline data on knowledge and perception of $\mathrm{CC}$, and the awareness of prevalence of climate sensitive diseases, in selected vulnerable areas of Bangladesh. We also collected baseline data on CC-related diseases such as malaria, Dengue fever, pneumonia \& diarrhoeal diseases. This paper focuses on knowledge and perception.

The results of this study provide useful information for policy makers and other stakeholders in the health sector of Bangladesh, so they can better respond to the challenges of CC and their effects on health.

\section{Methods \\ Design and setting}

This community-based cross-sectional study was carried out in 2012 in seven purposely-selected districts of Bangladesh, namely Bagerhat, Borguna, Coxbazar, Faridpur, Khulna, Sathkhira and Shirajganj. These are known to be cyclone, flood and salinity prone and hence constitute the most vulnerable areas to climate change [25]. The total population of the seven districts is $19,228,598$ individuals (census 2011). This survey was jointly conducted by the Climate Change and Health Promotion Unit (CCHPU) of the Ministry of Health and Family Welfare Bangladesh, Health Communication Network, Bangladesh, and the University of Newcastle, Australia.

\section{Sample size calculation}

We calculated the sample size for this study based on the precision of the prevalence of peoples' knowledge about CC. We assumed that approximately $50 \%$ of people have some knowledge about climate change. To estimate this proportion with a $95 \%$ confidence interval, 371 participants are required. We used a four-stage multilevel cluster sampling technique. Assuming a design effect of 2 for each stage, the total design effect is 16 , and the required sample size is $371 \times 16=5936$. To allow for a $10 \%$ non-response and for $1 \%$ missing data, the required sample size is 6670 . To evenly distribute the samples across districts we sampled 960 households from each of the seven districts, a total of 6720 households. In this study the knowledge of climate change was assessed only for the head of each household. 


\section{Study population}

The targeted study population was the total community of the seven vulnerable districts. Multistage sampling was used to select respondents for the study. We randomly selected four upazilas (sub-district) from each district as the primary sampling units. Then four unions (lowest administrative unit) per upazila (a total of 112 unions) were randomly selected, followed by 2 villages from each union. Thus a total of 224 villages were finally selected. The Bangladesh Bureau of Statistics (BBS) has standard Enumeration Areas (EA) and household listing for its census, which we used for EA and household selection. From each selected village, we randomly selected one EA and 30 households within each EA, using the BBS household numbers (total number of households $=6720$ ). From each household, we selected the head of the household as eligible participant, and obtained written consent or thumb impression. The consented participant provided information on other household members.

\section{Development of climate change knowledge-perception questionnaire}

The main instrument used for this study was a pretested, structured interviewer-administered interview schedule. We reviewed literature on $\mathrm{CC}$ for developing questionnaires on $\mathrm{CC}$ and health knowledge, perception, attitude and behaviour measures in relation to CC. We also contacted experts in the field to check for availability of a valid tool to assess CC knowledge. All perception questions on $\mathrm{CC}$ or health or $\mathrm{CC}$ extreme events had responses using various Likert-type answers such as 'Yes', 'No' or 'Did Not notice', or categorical options. The final interview schedule comprised a set of 37 questions on various aspects of climate change and health issues. As a part of the questionnaire, we also developed an observation checklist of household and community characteristics used by the interviewers (Additional files 1 and 2).

\section{Measurement of outcome variables}

The number of deaths from drowning and snake bites during extreme weather events was collected for the last 10 years preceding the interviews. The number of snake bites received by any household member during the previous 12 months was recorded. Prevalence of diarrhoea and pneumonia of children aged under five, and of Dengue fever and malaria in any household member, was collected and is presented elsewhere (unpublished observations by Kabir MI, Rahman MB, Smith W, Lusha MAF and Milton AH). Participants who indicated that they had heard of $\mathrm{CC}$ were asked for their explanation of $\mathrm{CC}$, followed by questions about its causes. The knowledge score was obtained from this information. We also asked CC related specific questions to all the respondents to assess their perception of $\mathrm{CC}$ irrespective of their knowledge about CC.

\section{Data Collection}

A structured draft questionnaire was developed and finalised after pre-testing in a similar rural setting. The final questionnaire was used to collect information on socio-demographic characteristics of the participants, and their knowledge and perception of climate change, extreme weather events and health. Other relevant information on health services and health education programmes at school was collected through face-to-face interviews.

A week-long training was provided to the data collectors. The trained 28 interviewers administered the questionnaire at household level under the direct supervision of 14 field supervisors over a two-week period. The quality-control team formed by the investigators monitored the performance of field personnel and supervisors through regular observation at the household level and regular checks of data for completeness. In $5 \%$ of study participants, the quality control team independently repeated data collection. The investigators checked each filled-up questionnaire to ensure that no information was missing; any error detected was corrected immediately at the field, sometimes by revisiting the household, before it was entered into the computer.

\section{Statistical analysis}

Collected data were entered into the computer and validated using the Statistical Package for Social Sciences (SPSS), version 21 by a series of logical and range checks, producing summary statistics and tables. Data were immediately copied onto the hard disks of two computers as soon as data verification was complete, and a copy was sent to the Principal Investigator at the University of Newcastle, Australia.

The summary statistics were reported as means with standard deviations (SD) for continuous variables, or as percentages with $95 \%$ confidence intervals (CI) for categorical variables. Sociodemographic variables and participants' responses were summarized and presented using frequency tables. Evidence of association between sociodemographic variables and knowledge of climate change was explored by cross-tabulation and measured using chi-square tests. Logistic regression models were applied to further explore the predictors of knowledge that were significant using bi-variate analysis. Where necessary, we also estimated dose-response relations using the 'contrast' post-estimation command after fitting a logistic regression in Stata (Stata 13 STATA Corporation, Texas, USA). We estimated the incidence densities of different events (e.g. death from drowning) by fitting 
intercept-only zero-inflated Poisson models using total number of household member as the offset. To adjust for the design effect of multistage sampling, we created sampling weights and incorporated them in the analyses using the 'svy:' command in Stata.

\section{Ethical approval and consent}

The study protocol was approved by the Bangladesh Medical Research Council and by the Human Research Ethics Committee of the University of Newcastle, Australia (H2012-0163). Written informed consent (thumb impression in case of writing inability) was obtained from the heads of the household after the written information note was read out at the beginning of the interview.

\section{Results}

A total of 6720 participants from 224 cluster villages in Bangladesh were interviewed. Each cluster contains 30 households in each of 56 unions within 28 upazilas in 7 coastal districts.. All participants were head of their households, comprising 6245 males (92.9 \%) and 475 females $(7.1 \%)$. The mean age of the participants was 44.7 years with a standard deviation (SD) of 13.5 years. The mean duration of stay in the locality was 30 years (median 25, SD 15). The majority was in their middle age (45-60 years, $55.7 \%)$, currently married (91.6\%), and had experienced extreme weather events (95.7\%) during their stay in the locality. As the study was conducted in coastal and rural Bangladesh the participants were mainly living in non-brick houses (91.3\%), and their main source of drinking water were either shallow $(43.7 \%)$ or deep (41.9\%) wells. Participants came largely from low socioeconomic backgrounds: only $9.6 \%$ had post-secondary education or higher; the majority were day labourers or farmers (60\%), and only $10 \%$ earned a monthly income above BDT 12000 (1 USD = 77 Bangladeshi Taka.) (Table 1).

Table 2 shows the responses of the participants on their climate change knowledge. The majority $(n=6720)$ of the research participants $(54.2 \%)$ acquired knowledge about CC from some source and $45.8 \%$ had not heard of $\mathrm{CC}$ at all. Among the knowledgeable participants $(n=3645)$, the majority felt that CC was manifested in an increase in $(83.2 \%)$. More than half $(53.9 \%)$ attributed a change in the pattern/periodicity of rainfall to CC, $43.2 \%$ felt a colder winter than usual cold, and more than one third saw $\mathrm{CC}$ in a higher incidence of cyclones or tidal waves (36.5\%). Some thought that frequent flooding (13.8\%) and water logging $(8.7 \%)$ are an effect of CC. When participants were asked about causes for CC $(n=3645)$, responses varied from deforestation (81 \%) to rapid urbanization and changes in life style (1.9\%). More
Table 1 Characteristics o00f the participants $(n=6720)$

\begin{tabular}{|c|c|}
\hline Variable & Frequency (\%) \\
\hline Gender (Male) & $6245(92.9)$ \\
\hline Age $($ Mean $\pm S D)$ in years & $44.7 \pm 13.5$ \\
\hline Duration of stay in this locality (Mean, median, SD) in years & $30,25, \pm 15$ \\
\hline \multicolumn{2}{|l|}{ Education of Respondent } \\
\hline No formal education & $2923(43.5)$ \\
\hline Primary & $2013(30.0)$ \\
\hline Secondary & $1143(17.0)$ \\
\hline Higher Secondary & $496(7.4)$ \\
\hline Graduate and above & $145(2.2)$ \\
\hline \multicolumn{2}{|l|}{ Occupation of Respondent } \\
\hline Farmer & $1988(29.6)$ \\
\hline Day labourer & $2047(30.5)$ \\
\hline Service holder & $524(7.8)$ \\
\hline Small and medium business & $1066(15.9)$ \\
\hline House wife & $299(4.5)$ \\
\hline Fisherman & $252(3.8)$ \\
\hline Unemployed & $51(0.8)$ \\
\hline others & $493(7.3)$ \\
\hline \multicolumn{2}{|l|}{ Type of House } \\
\hline Kachca (Bamboo, Tree Leaves)) & $925(13.7)$ \\
\hline Pakka (Brick) & $121(1.8)$ \\
\hline Tin (Corrugated sheet) & $5211(77.6)$ \\
\hline others & $462(6.9)$ \\
\hline \multicolumn{2}{|l|}{ Total household monthly income } \\
\hline \multicolumn{2}{|l|}{ Income (In Bangladeshi Taka, 1 US\$ = 80 BDT approx..) } \\
\hline$<4000$ BDT & $1436(21.4)$ \\
\hline $4000-8000$ BDT & $3485(51.9)$ \\
\hline 8000-12000 BDT & $1127(16.7)$ \\
\hline$>12000$ BDT & $672(10)$ \\
\hline \multicolumn{2}{|l|}{ Drinking water source } \\
\hline Shallow Tube well & $2936(43.7)$ \\
\hline Deep tube well & $2822(42.0)$ \\
\hline Supply water & $36(0.5)$ \\
\hline Untreated water & $322(4.8)$ \\
\hline Treated water & $524(7.8)$ \\
\hline Rain water & $50(0.7)$ \\
\hline Others & $30(0.5)$ \\
\hline
\end{tabular}

than half of the participants felt that $\mathrm{CC}$ was due to population growth (56.9\%). As many as $28.1 \%$ believed that industrial effluents are one of the cause, $25.1 \%$ chose black exhaust from vehicles, and $4.9 \%$ attributed CC to excessive carbon emissions by the developed countries. In terms of the source of knowledge, television was the most commonly mentioned 
Table 2 Participants' knowledge about climate change

\begin{tabular}{|c|c|}
\hline Variable & Frequency (\%) \\
\hline \multicolumn{2}{|l|}{$\begin{array}{l}\text { Have you heard of what 'Climate Change' means } \\
\text { from any source? }\end{array}$} \\
\hline Yes & $3645(54.2)$ \\
\hline No & $3073(45.8)$ \\
\hline \multicolumn{2}{|l|}{$\begin{array}{l}\text { What is the main source of your information on } \\
\text { climate change? }^{\text {? }}\end{array}$} \\
\hline Newspaper & $416(11.4)$ \\
\hline Weekly magazine & $51(1.4)$ \\
\hline Radio & $1423(39.0)$ \\
\hline Television & $2026(55.6)$ \\
\hline Neighbours & $1999(54.8)$ \\
\hline Health workers & $513(14.0)$ \\
\hline Teachers & $164(4.5)$ \\
\hline Family members/Relatives & $12(0.33)$ \\
\hline Imams of the mosque & $1(0.03)$ \\
\hline NGO workers & $5(0.14)$ \\
\hline Personal involvement in Training & $1(0.03)$ \\
\hline \multicolumn{2}{|l|}{ Type of change in climate ${ }^{a}$} \\
\hline Excessive Temperature & $3033(83.2)$ \\
\hline Excessive cold & $1575(43.2)$ \\
\hline Change of pattern of rainfall & $1967(53.9)$ \\
\hline Frequent cyclone or tidal wave & $1329(36.5)$ \\
\hline Frequent Flood & $502(13.8)$ \\
\hline Water logging & $317(8.7)$ \\
\hline \multicolumn{2}{|l|}{ Don't know/Don't understand } \\
\hline \multicolumn{2}{|l|}{ Causes or reasons for climate change ${ }^{a}$} \\
\hline Deforestation & $2953(81.0)$ \\
\hline Industrial effluents & $1023(28.1)$ \\
\hline Population Growth & $2075(56.9)$ \\
\hline Black smoke of vehicles & $914(25.1)$ \\
\hline Excessive carbon emission by the developed country & $177(4.9)$ \\
\hline Rapid urbanization and changes in life style & $71(1.9)$ \\
\hline Others & $32(0.9)$ \\
\hline
\end{tabular}

${ }^{a}(n=3645)$ percentage total may add up to more than $100 \%$ as multiple responses were permissible

(55.6\%), followed by neighbours $(54.8 \%)$ and radio (39\%) (Table 2).

We also asked all the participants CC-related questions, irrespective of their knowledge about $\mathrm{CC}$, to explore their perception and awareness towards the influence of CC on human health and the environment (Table 3). Participants observed increased episodes of extreme weather events such as drought $(85.5 \%)$, cyclones/floods $(61.3 \%)$, and tidal waves $(42.1 \%)$ in the past 10 years preceding the study. Most of them $(91.9 \%)$ observed a change in rainfall pattern over the last
10 years. Although $54.2 \%$ of participants had heard of CC, $94.5 \%$ had observed changes in climate. Some of the participants perceived that the sea water level had increased (17.4\%), while $46.7 \%$ had not noticed this.in the coastal areas. About $29 \%$ of the total households were not living in the coastal area but they were also been asked the question.

In addition to the environmental elements, participants' perception of CC-related health effects was also limited. Most of the participants $(80 \%)$ believed there will be a scarcity of fresh water due to increase in salinity, as a majority (53.3 \%) had observed increased water salinity in the past 10 years preceding the interview. About $61 \%$ were aware of increasing health risk such as high blood pressure, pregnancy outcomes because of increase in salinity. In terms of food security, almost $71 \%$ indicated that food crop production would be negatively affected. The incidence of deaths from drowning and snake bite during the extreme weather events of the last 10 years were 32 (95 \% CI: 27 to 38 ) and 6.8 (95\% CI: 3.5 to 13.2 ), respectively, per 100,000 population per year. The incidence of snake bite for the year preceding the study period was 36 (95\% CI: 29 to 45). Almost all participants $(97.8 \%)$ believed health care expenditure increased after extreme weather events (Table 3 ).

Cross-tabulation was done to examine the association between sociodemographic variables and the knowledge of the participants on CC. Age, sex, education, occupation, monthly family income, nearby government health facility, and presence of any school in the survey area were significantly associated with the knowledge of participants (Table 4).

Education was significantly associated with CC knowledge in the univariate analyses. In the multivariable analysis, education, sex and availability of school in the area were significantly associated with knowledge of CC and its health impacts. A clear dose-response association was observed with educational level (P-for linear trend from logistic regression <0.001). Respondents from a locality with a school were three times more likely to have knowledge about $\mathrm{CC}$ and its impact on health than those who did not have a school in their locality (Table 5).

\section{Discussion}

This study, to the best of our knowledge, is the first large-scale quantitative attempt to assess the knowledge and perceptions of the vulnerable communities in Bangladesh about CC and its impact on health. The findings provide important insights into what people think and believe from their experience at the grassroots level. The household participants were from the rural areas that are vulnerable to climate change [25]. Since we interviewed the heads of the households, most of the 
Table 3 Participants' perception and awareness towards influence of climate change on human health and the environment $(N=6716)$

\begin{tabular}{|c|c|c|c|}
\hline Influence of Climate Change & YesN (\%) & Unchanged $^{\mathrm{a}} /$ Not applicable $^{\mathrm{b}} \mathrm{N}(\%)$ & Did notnoticeN (\%) \\
\hline Increased episode of cyclone/flood in the last 10 years & $4120(61.3)$ & $188(2.8)^{a}$ & 0 \\
\hline Increased episode of tidal wave in the last 10 years & $2823(42.1)$ & $467(6.9)^{\mathrm{a}}$ & $2846(42.5)$ \\
\hline Increased episode of drought in the last 10 years & $5748(85.5)$ & $229(3.4)^{\mathrm{a}}$ & 139 \\
\hline Change in rainfall pattern in the last 10 years & $6172(91.9)$ & 0 & 0 \\
\hline Change in sea water level in the last 10 years & $1169(17.4)$ & $1920(28.6)^{b}$ & $3140(46.7)$ \\
\hline Increased salinity of water in the last 10 years & $3582(53.3)$ & 0 & 0 \\
\hline Scarcity of fresh water due to increase in salinity & $5378(80)$ & 0 & 0 \\
\hline Increased health risk due to increase in salinity & $4073(60.6)$ & 0 & 0 \\
\hline Reduced food crop production in the last 10 years & $4761(70.8)$ & 0 & 0 \\
\hline Death from drowning in the last 10 years & $132(32,95 \% \mathrm{Cl}: 27 \text { to } 38)^{\mathrm{c}}$ & 0 & 0 \\
\hline Death from snake bite in the last 10 years & $26(6.8,95 \% \mathrm{Cl}: 3.5 \text { to } 13.2)^{\mathrm{c}}$ & 0 & 0 \\
\hline Number of snake bite in the last year & $207(36,95 \% \mathrm{Cl}: 29 \text { to } 45)^{\mathrm{c}}$ & & \\
\hline Increased health care expenditure after extreme weather events & $6572(97.8)$ & 0 & 0 \\
\hline
\end{tabular}

anchanged is meant for the increased episodes of extreme weather events

${ }^{\mathrm{b}}$ Not applicable means the households were not in coastal area

Incidence densities per 100,000 per year

participants were male. The majority of participants were relatively poor and had little formal education with an agro-based livelihood, which is consistent with the national level data [26]. However, they have a clear perception about the change in climate and associated variability in temperature, rainfall, salinity and sea level, and the effect of these changes on their health. Knowledge and perception studies on CC and its associated health impact had been conducted in the Philippines [27], Vietnam [28], United States of America, Canada, and Malta [29], Nigeria [30], Nepal [31], Bangladesh [24], India [32], Australia [33], and China [34]. A previous cross-sectional study of two villages in Bangladesh had the limitation of generalizability of their findings regarding households' perception of CC and human health risks [24]. In our study, we used a similar approach but our sample size was larger, more representative and better distributed geographically among vulnerable communities.

Out of 6720 participants, slightly more than fifty four percent had knowledge of 'climate change'. Almost $46 \%$ of the vulnerable community had not heard about CC, which might be a concern for the policy makers in health sector to provide adequate community level training on CC and its impact on health through the community clinics. The results are similar in two other studies conducted in LDCs, Nigeria [30] and Nepal [35], where $54 \%$ and $51.3 \%$, respectively, of the participants reported they know about 'climate change'. From our study, of those who had knowledge about $\mathrm{CC}$, the majority named mass media (television, radio, newspaper etc.) and neighbours as their source. Very few people mentioned hearing about $\mathrm{CC}$ from teachers, Imams, health workers and non-governmental organization (NGO) workers. This indicates that mass media and discussions in the neighbourhood are important source of information. Opinion leaders such as teachers and imams of mosques, and service providers such as health workers and NGO workers need formal training on CC and its impact on health in the field level. There is a sectoral gap of engagement from the government system with health and environmental issues. This is consistent with the study conducted in Nepal [35]. Overall, our study highlights that mass media coverage, especially through community radio and television, is currently the major source of information about CC.

Most of the participants believed that there had been a change in climate in the 10 years preceding the interview. This perception is supported by data collected at national level on the climate in Bangladesh. Data from the Bangladesh Meteorological Department (BMD) for the periods of 1951-2011 show that for any ten-year period the temperature was higher and rainfall less predictable than in the preceding ten years [36]. Other countries such as Jamaica, Vietnam, and Nepal reported identical findings for their studies among a similar population $[23,28,35]$. With regard to causes or reasons for CC, most of our participants mentioned deforestation followed by population growth and industrial effluents. The other less scientific reasons given by the participants, such as black smoke of vehicles, could be due to their low level of education and less exposure to the scientific facts by virtue of their occupation. These results also supported by other studies carried out in 
Table 4 Association between socio-demographic variables and knowledge of climate change

\begin{tabular}{|c|c|c|c|c|}
\hline \multirow[t]{2}{*}{ Variable } & \multicolumn{3}{|c|}{ Knowledge of climate change } & \multirow[t]{2}{*}{ Statistics } \\
\hline & No (\%) & Yes (\%) & Total (\%) & \\
\hline \multicolumn{5}{|l|}{ Age-group } \\
\hline Young (<30 years) & $384(51.7)$ & $359(48.3)$ & $743(100.0)$ & $x^{2}=13.84$ \\
\hline Early adulthood (30 - 45 years) & $1243(46.0)$ & $1458(54.0)$ & $2710(100.0)$ & $d f=3$ \\
\hline Middle age (45 - 60 years) & $929(44.3)$ & $1167(55.7)$ & $2096(100.0)$ & $p=0.003$ \\
\hline Old age (>60 years) & $517(43.9)$ & $659(56.1)$ & $1176(100.0)$ & \\
\hline Total & $3073(45.8)$ & $3643(54.2)$ & $6716(100.0)$ & \\
\hline \multicolumn{5}{|l|}{ Sex } \\
\hline Male & $2811(45.0)$ & $3430(55.0)$ & $6241(100.0)$ & $x^{2}=18.20$ \\
\hline Female & $262(55.1)$ & $213(44.9)$ & $475(100.0)$ & $d f=1$ \\
\hline Total & $3073(45.8)$ & $3643(54.2)$ & $6716(100.0)$ & $p<0.001$ \\
\hline \multicolumn{5}{|l|}{ Education of Respondent } \\
\hline No formal education & $1571(53.8)$ & $1350(46.2)$ & $2921(100.0)$ & $x^{2}=334.70$ \\
\hline Primary & $993(49.4)$ & $1018(50.6)$ & $2011(100.0)$ & $d f=4$ \\
\hline Secondary & $383(33.5)$ & $760(66.5)$ & $1143(100.0)$ & $p<0.001$ \\
\hline Higher Secondary & $107(21.6)$ & $389(78.4)$ & $496(100.0)$ & \\
\hline Graduate and above & $19(13.1)$ & $126(86.9)$ & $145(100.0)$ & \\
\hline Total & $3073(45.8)$ & $3643(54.2)$ & $6716(100.0)$ & \\
\hline \multicolumn{5}{|l|}{ Occupation of Respondent } \\
\hline Farmer & $1025(51.6)$ & $961(48.4)$ & $1986(100.0)$ & $x^{2}=180.04$ \\
\hline Day labourer & $1011(49.4)$ & $1034(50.6)$ & $2045(100.0)$ & $d f=7$ \\
\hline Service holder & $136(25.9)$ & $388(74.1)$ & $524(100.0)$ & $p<0.001$ \\
\hline Small and medium business & $398(37.3)$ & $668(62.7)$ & $1066(100.0)$ & \\
\hline House wife & $169(56.5)$ & $130(43.5)$ & $299(100.0)$ & \\
\hline Fisherman & $126(50.0)$ & $126(50.0)$ & $252(100.0)$ & \\
\hline Unemployed & $19(37.2)$ & $32(62.8)$ & $51(100.0)$ & \\
\hline others & $189(38.3)$ & $304(61.7)$ & $493(100.0)$ & \\
\hline Total & $3073(45.8)$ & $3643(54.2)$ & $6716(100.0)$ & \\
\hline \multicolumn{5}{|l|}{ Total household monthly income } \\
\hline \multicolumn{5}{|l|}{ Income (cat) } \\
\hline$<4000 \mathrm{BDT}$ & $742(51.8)$ & $692(48.2)$ & $1434(100.0)$ & $x^{2}=71.96$ \\
\hline 4000-8000 BDT & $1653(47.5)$ & $1830(52.5)$ & $3483(100.0)$ & $d f=2$ \\
\hline$>8000$ BDT & $678(37.7)$ & $1121(62.3)$ & $1799(100.0)$ & $p<0.001$ \\
\hline Total & $3073(45.8)$ & $3643(54.2)$ & $6716(100.0)$ & \\
\hline \multicolumn{5}{|l|}{ Nearby government health facility } \\
\hline District Hospital & $127(38.2)$ & $205(61.8)$ & $332(100.0)$ & $x^{2}=68.79$ \\
\hline Upazila health complex & $790(39.0)$ & $1235(61.0)$ & $2025(100.0)$ & $d f=3$ \\
\hline Union health centre & $1214(49.6)$ & $1233(50.4)$ & $2447(100.0)$ & $p<0.001$ \\
\hline Community clinic & $942(49.3)$ & $970(50.7)$ & $1912(100.0)$ & \\
\hline Total & $3073(45.8)$ & $3643(54.2)$ & $6716(100.0)$ & \\
\hline \multicolumn{5}{|l|}{ Any school in the survey area } \\
\hline No & $101(66.9)$ & $50(33.1)$ & $151(100.0)$ & $x^{2}=27.79$ \\
\hline Yes & $2972(45.3)$ & $3593(54.7)$ & $6565(100.0)$ & $d f=1$ \\
\hline Total & $3073(45.8)$ & $3643(54.2)$ & $6716(100.0)$ & $p<0.001$ \\
\hline
\end{tabular}


Table 5 Predictor of knowledge of climate change from logistic regression analyses

\begin{tabular}{lll}
\hline Predictor & Unadjusted odds ratio $(95 \% \mathrm{Cl})$ & Adjusted odd Ratio $(95 \% \mathrm{Cl})$ \\
\hline Sex (Female) & $0.61(0.46-0.82)$ & $0.71(0.53-0.95)$ \\
Age & $1.002(0.995-1.008)$ & $1.003(0.99-1.001)$ \\
Education ${ }^{\mathrm{a}, \mathrm{b}}$ & & 1 \\
$\quad$ No formal education & 1 & $1.02(0.72-1.46)$ \\
$\quad$ Primary & $1.02(0.73-1.43)$ & $2.03(1.39-2.98)$ \\
$\quad$ Secondary & $2.06(1.43-2.97)$ & $3.06(1.75-5.34)$ \\
$\quad$ Higher Secondary & $3.15(1.83-5.42)$ & $6.90(3.07-15.48)$ \\
$\quad$ Graduate and above & $7.16(3.17-16.19)$ & $3.16(1.32-7.54)$ \\
\hline
\end{tabular}

${ }^{\mathrm{a}} P<0.001$, for overall significance of the variable in the multivariable model

${ }^{\mathrm{b}} \mathrm{P}<0.001$, for linear trends in the odds ratios

Bangladesh and other LDCs such as Nigeria and small island countries such as Trinidad and Tobago [30, 37].

The perceptions of vulnerable people are also consistent with the national level findings. Annual maximum temperature over Bangladesh is increasing by $0.09{ }^{\circ} \mathrm{C}$ but annual minimum temperature is increasing by $0.10{ }^{\circ} \mathrm{C}$. The rate of increase of the annual minimum temperature is higher than that of the annual maximum temperature [38]. The annual average rainfall over Bangladesh is increasing by about $10.6 \mathrm{~mm}$ per decade whereas monsoonal rainfall over Bangladesh is decreasing by $7.6 \mathrm{~mm}$ per decade [39]. The participants also had the perceptions that episodes of extreme weather events such as cyclones, floods, storm surges, heavy rains within a short time, and droughts had increased compared to ten years earlier. It has been observed from the BMD database that the frequency of cyclones has been increasing in every decade since the 1970s [40]. Bangladesh evidenced ten severe floods during the last 40 years. Every 4-5 years severe floods inundate about $60 \%$ of the country. In 2007, two successive and damaging floods occurred in the same season [41]. It has been found that the frequency of heavy rainfall in June, July and August has increased over the last few decades [39].

With regard to the sea level rise, the perception of the coastal participants from Borguna, Bagerhat, Cox's bazar, Khulna and Satkhira is supported by historic data on sea water level rise in three of the coastal districts: Bagerhat, Satkhira and Khulna. These data show that the mean annual water level has risen by $4.5 \mathrm{~mm} /$ year in about $20 \%$ of the total area of these three districts, which is attributed to the global sea level rise associated with anthropological activities [42]. The perception of our participants regarding salinity intrusion and increase in water salinity is also supported by another evidence-based study [43].
Participants strongly agreed that agricultural food crop production had declined during the last 10 years, and population health had been adversely affected by $\mathrm{CC}$ in their villages. This has serious implications regarding food security and livelihood. The number of deaths from drowning and snake bites supports other communitybased studies in Bangladesh [44, 45], although the incidence was higher in our study because of the increase in the number of extreme weather events. This finding has important implications for local level planning and policy development. Moreover, understanding the concerns of people about increased health care expenditure after the extreme weather events may help policy makers to develop and implement apprpriate adaptive measures for health adaptation.

In our study, heads of households with higher levels of education were more likely to be aware of $\mathrm{CC}$ than those with lower education levels. Other studies also reported that CC awareness most strongly depended on the respondent's level of education [27, 31, 46]. In the course of educational development of Bangladesh the availability of schools in rural and remote areas was a major factor in students' drop out and people's education level. Our study suggests that schools play an important role for increasing knowledge on CC and associated adaptation issues.

Our study has several strengths. We surveyed a large number of households. Furthermore, the study recruited participants from an array of geographic locations known for their susceptibility to CC. This makes the findings from this study relevant to other CC-vulnerable areas of Bangladesh. A further strength is the collection of data with local context in association with how extreme weather events were experienced. The findings will be useful for developing strategies to induce individual and community behaviour change to better cope with $\mathrm{CC}$ and make adaptations to minimise health issues. The findings could be 
used as baseline for a future cohort study. There were a few limitations to the study, including the recall bias, as we relied on the previous experiences and subjective judgements of the head of the households. As $92.9 \%$ of participants were male, female perception was not considered. Peoples' perception on CC and its impact on health could not be checked against real-time data. Such data could be collected in future to allow estimating the accuracy of community perceptions.

\section{Conclusion}

The knowledge level of the study participants on CC was more than our assumption (54\%) and the perception of vulnerable communities on changing climatic factors and their impacts on health was higher (94\%). The public health sector needs to be engaged more in primary health care by training health workers at field level to address CC and health issues. Level of education is an influential factor to understand $\mathrm{CC}$ and its impact on health. Based on these key findings, policy makers can develop effective communication strategies for the vulnerable communities in Bangladesh and similar LDCs to protect human health from the adverse effect of CC. To protect future generations child-centred educational intervention at school level on CC and health adaptation could be explored by further research [47].

\section{Additional files}

Additional file 1: Survey Questionnaire in Local laguage Bengali. (PDF $2502 \mathrm{~kb}$ )

Additional file 2: Survey Questionnaire English version. (PDF $51 \mathrm{~kb}$ )

\begin{abstract}
Abbreviations
AR5: The fifth Assessment Report of IPCC; BBS: Bangladesh Bureau of Statistics; BDT: Bangladeshi Taka; BMD: Bangladesh Meteorological Department; CC: Climate change; CCHPU: the Climate Change and Health Promotion Unit of the Ministry of Health and Family Welfare; IPCC: Intergovernmental Panel on Climate Change; LDC: Least Developed Countries; USD: United States Dollar; WHO: World Health Organization.
\end{abstract}

\section{Competing interest}

The authors declare that they have no competing interests.

\section{Authors' contributions}

MIK designed the study, developed the questionnaire, trained the data collectors, supervised the data collection and wrote the paper. MBR analysed the data and contributed to writing the paper. WS contributed to the interpretation of the findings. MAFL supervised the data collection, data entry and contributed to writing the paper. SA contributed with assistance in weighting the data. AHM contributed to the overall development of study concept, design, overall supervision of MIK and finalization of the paper. All authors read and approved the final manuscript.

\section{Acknowledgement}

We acknowledge the financial support provided for this study by the Climate Change and Health Promotion Unit (CCHPU) of Ministry of Health and Family Welfare, Bangladesh. We thank the study participants, and the project director, project staff, trainers, data collectors and Youth Think Tank members of CCHPU. We are grateful to the Bangladesh Medical Research Council (BMRC) for their kind support. Finally, the authors thank Claudia Koller for assistance with editing this manuscript.

\section{Author details}

${ }^{1}$ Centre for Clinical Epidemiology and Biostatistics, School of Medicine and Public Health, Faculty of Health and Medicine, The University of Newcastle, Newcastle, NSW 2308, Australia. ${ }^{2}$ National Institute of Preventive and Social Medicine, NIPSOM, Mohakhali, Dhaka, Bangladesh. ${ }^{3}$ School of Public Health and Community Medicine, Faculty of Medicine, University of New South Wales, Sydney, Australia. ${ }^{4}$ Climate Change and Health Promotion Unit, Ministry of Health and Family Welfare, Dhaka, Bangladesh.

Received: 15 July 2015 Accepted: 7 March 2016

Published online: 15 March 2016

\section{References}

1. McMichael AJ. Climate change and health: information to counter the White House Effect. Int J Epidemiol. 2001;30(4):655-7.

2. Neira M, Bertollini R, Campbell-Lendrum D, Heymann DL. The year 2008: a breakthrough year for health protection from climate change? Am J Prev Med. 2008;35(5):424-5.

3. IPCC. IPCC Fifth Assessment Synthesis Report. Geneva: Switzerland; 2014.

4. Ebi KL, Lewis ND, Corvalan C. Climate variability and change and their potential health effects in small island states: information for adaptation planning in the health sector. Environ Health Perspect. 2006;114(12): 1957-63.

5. Campbell-Lendrum D, Woodruff R. Comparative risk assessment of the burden of disease from climate change. Environ Health Perspect. 2006; 114(12):1935-41.

6. Cheng JJ, Berry P. Health co-benefits and risks of public health adaptation strategies to climate change: a review of current literature. Int J Public Health. 2013;58(2):305-11.

7. Ebi KL, Semenza JC. Community-based adaptation to the health impacts of climate change. Am J Prev Med. 2008:35(5):501-7.

8. Brouwer R, Akter S, Brander L, Haque E. Socioeconomic vulnerability and adaptation to environmental risk: a case study of climate change and flooding in Bangladesh. Risk Anal. 2007;27(2):313-26.

9. Sheffield PE, Landrigan PJ. Global climate change and children's health: threats and strategies for prevention. Environ Health Perspect. 2011;119(3): 291-8.

10. Akompab DA et al. Awareness of and attitudes towards heatwaves within the context of climate change among a cohort of residents in Adelaide, Australia. Int J Environ Res Public Health. 2013:10:1-17.

11. Bai $L$ et al. Rapid warming in Tibet, China: public perception, response and coping resources in urban Lhasa. Environ Health. 2013;12:71.

12. Yu H et al. Public perception of climate change in China: results from the questionnaire survey. Nat Hazards. 2013:69:459-72.

13. Hess JJ, Eidson M, Tlumak JE, Raab KK, Luber G. An Evidence-Based Public Health Approach to Climate Change Adaptation. Environ Health Perspect. 2014;122(11):1177-86.

14. Maibach EW et al. Climate change and local public health in the United States: preparedness, programs and perceptions of local public health department directors. PLoS One. 2008;3:e2838.

15. Bouzid M, Hooper L, Hunter PR. The effectiveness of public health interventions to reduce the health impact of climate change: a systematic review of systematic reviews. PLoS One. 2013;8(4), e62041.

16. Bierbaum R, Smith JB, Lee A, Blair M, Carter L, Chapin FS, et al. A comprehensive review of climate adaptation in the United States: more than before, but less than needed. Mitig Adapt Strat Gl. 2013;18(3):361-406.

17. IPCC, Parry ML, et al. Climate change: impacts, adaptation and vulnerability. In: Contribution of Working Group II to the Fourth Assessment Report of the Intergovernmental Panelon Climate Change. Cambridge: Cambridge University Press; 2007a. p. 331-413.

18. Haque MA, Yamamoto SS, Malik AA, Sauerborn R. Households' perception of climate change and human health risks: a community perspective. Environ Health. 2012;11:1.

19. Haque MA, Budi A, Azam Malik A, Suzanne Yamamoto S, Louis VR, Sauerborn R. Health coping strategies of the people vulnerable to climate change in a resource-poor rural setting in Bangladesh. BMC Public Health. 2013;13:565. 
20. Poortinga W, Pidgeon N. Public Perception of Risk Science and Governance: Main Findings of a British Survey of Five Risk Cases. Norwich: University of East Anglia; 2003.

21. Bickerstaff $\mathrm{K}$, Walker $\mathrm{G}$. Public understandings of air pollution: the 'localization' of environmental risk. Glob Environ Change. 2001;11:133-45.

22. Read D, Bostrom A, Morgan MG, Fischhoff B, Smuts T. What do people know about global climate change? Part 2. Survey studies of educated lay people. Risk Anal. 1994;14:971-82.

23. Planning Institute of Jamaica. Report on Climate Change Knowledge, Attitude and Behavioural Practice Survey. Kingston: Caribbean Institute of Media and Communication Knowledge; 2012.

24. Guillemot J, Ebi K, Kabir I, Nguyen T, Malkawi M. Scaling up communitybased adaptation to protect health from climate change. In: Schipper $E_{\text {, }}$ Ayers J, Reid H, Huq S, Rahman A editors. Community- based adaptation to climate change: scaling it up. London, New York: Routledge, Taylor and Francis group; 2014. p. 155-71.

25. Rabbani MG, Rahman AA, Shoef IJ, Khan ZM. Climate Change and Food Security in Vulnerable Coastal Zones of Bangladesh, Food Security and Risk Reduction in Bangladesh. Springer; 2015. pp. 173-185.

26. Chowdhury AMR, Bhuiya A, Chowdhury ME, Rasheed S, Hussain Z, Chen LC. The Bangladesh paradox: exceptional health achievement despite economic poverty, The Lancet. 2013;382(9906):1734-1745.

27. Combest-Friedman C, Christie P, Miles E. Household perceptions of coastal hazards and climate change in the CentralPhilippines. J Environ Manage. 2012;112:137-48.

28. Toan DTT, Kien VD, Giang KB, Hoang VM, Wright P. Perceptions of climate change and its impact on human health: an integrated quantitative and qualitative approach. Glob Health Action. 2014;7:23025

29. Kerlof KA et al. Public Perceptions of Climate Change as a Human Health Risk: Surveys of the United States, Canada and Malta. Int J Environ Res Public Health. 2010;7:2559-606.

30. Asekun-Olarinmoye EO et al. Public perception of climate change and its impact on health and environment in rural south-western Nigeria. Research and Reports in Tropical Medicine. 2014;5:1-10.

31. Mishra SR, Bhandari PM, Issa R, Neupane D, Gurung S, Khanal V. Climate change and adverse health events: community perceptions from the Tanahu district of Nepal. Environ Res Lett. 2015;10(3):034007.

32. Chaudhary P, Bawa KS. Local perceptions of climate change validated by scientific evidence in the Himalayas. Biol Lett. 2011;7:767_70.

33. Akter S, Bennett J. Household perceptions of climate change and preferences for mitigation action: the case of the Carbon Pollution Reduction Scheme in Australia. Clim Change. 2011.

34. Wei J et al. Perception, attitude and behaviour in relation to climate change: A survey among CDC health professionals in Shanxi province, China. Environ Res. 2014;134:301-8.

35. Banstola A et al. Knowledge related to climate change and willingness to act for adaptation and mitigation practices in rural Nepal. Vietnam Journal of Public Health. 2013;2:22-32.

36. Endo N, Matsumoto J, Hayashi T, Terao T, Murata F, Kiguchi M, Yamane Y, Alam MS. Trends in Precipitation Characteristics in Bangladesh from 1950 to 2008. SOLA. 2015;11:113-117.

37. Rawlins SC, Chen A, Rawlins JM, Chadee DD, Legall G. A knowledge, attitude and practices study of the issues of climate change/variability impacts and public health in Trinidad and Tobago, and St Kitts and Nevis. West Indian Med J. 2007;56:115-21.

38. Caesar J, Janes T, Lindsay A, Bhaskaran B. Temperature and precipitation projections over Bangladesh and the upstream Ganges, Brahmaputra and Meghna systems. Environ Sci: Processes Impacts. 2015;17(6):1047-1056.

39. Shahid S. Trends in extreme rainfall events of Bangladesh. Theor Appl Climatology. 2011;104(3-4):489-499.

40. Quadir DA, lqbal MA. Tropical Cyclones: Impacts on coastal livelihoods: Investigation of the coastal inhabitants of Bangladesh. Dhaka: IUCN country Office; 2008.

41. Dewan TH. Societal impacts and vulnerability to floods in Bangladesh and Nepal. Weather Climate Extremes. 2015;7:36-42.

42. Brammer H. Bangladesh's dynamic coastal regions and sea-level rise. Climate Risk Management. 2014;1:51-62.

43. Miah MU. Assessing long term impacts of vulnerabilities on crop production due to climate change in the coastal areas of Bangladesh. Dhaka: Final Report PR \#10/08,Food Planning and Monitoring Unit (FPMU), Ministry of Food, supported by USAID, EU; 2010.
44. Rahman A, Linnan M, Mashreky SR, Hossain MJ, Rahman F. The prevalence of naturally acquired swimming ability among children in Bangladesh: a cross sectional survey. BMC Public Health. 2014;14(1):404.

45. Milton AH, Rahman R, Faiz MA, Selim S, Rahman B, Basher A, Jones A, Catherine D, Hossain M, Islam Z, Ahmed H. Annual Incidence of Snake Bite in Rural Bangladesh. Plos Neglected Tropical Diseases. 2010;4:10. e860.

46. Semenza JC, Wilson DJ, Parra J, Bontempo BD, Hart M, Sailor DJ, et al. Public perception and behaviour change in relationship to hot weather and air pollution. Environ Res. 2008;107:401-11.

47. Kabir MI, Rahman MB, Smith W, Lusha MAF, Milton AH. Child centred approach to climate change and health adaptation through schools in Bangladesh: a cluster randomised intervention trial. PLoS One. 2015;10(8), e0134993. doi:10.1371/journal.pone.0134993.

\section{Submit your next manuscript to BioMed Central and we will help you at every step:}

- We accept pre-submission inquiries

- Our selector tool helps you to find the most relevant journal

- We provide round the clock customer support

- Convenient online submission

- Thorough peer review

- Inclusion in PubMed and all major indexing services

- Maximum visibility for your research

Submit your manuscript at www.biomedcentral.com/submit
Ciomed Central 